\title{
Morphometric Study of Lumbar Vertebrae in South Indian Population
}

\author{
Shifa Jawahar Ali ${ }^{1}$ and S. Sangeetha ${ }^{2}$ \\ ${ }^{1}$ Saveetha Dental college and Hospitals, Saveetha Institute of Medical and \\ Technical Sciences (SIMATS), Saveetha University, Chennai - 600077, India \\ ${ }^{3}$ Lecturer, Department of Anatomy,Saveetha Dental College and Hospitals, \\ Saveetha Institute of Medical and Technical Sciences (SIMATS), Saveetha \\ University, Chennai - 600077, India
}

\begin{abstract}
The lumbar vertebrae consists of five cylindrical bones that form the spine in the lower back. These vertebrae carry all of the overlying body's weight while providing flexibility and movement to the trunk region. They also protect the delicate spinal cord and nerves within their vertebral canal. The dimensions of lumbar vertebrae should be understood for clinical diagnosis of diseases. The aim of the study is to study about the lumbar vertebrae morphometrically. A total number of 70 dry human lumbar vertebrae were used of which 40 were of males and 30 were of females were obtained from the Department of Anatomy, Saveetha Dental college and Hospitals, Chennai and Sri Ramachandra Medical College and Research Institute, Chennai.The anteroposterior body diameter, transverse body diameter, interpedicular distance and midsagittal diameter was measured using Vernier caliper.The average, mean and standard deviation were calculated. In the present study, the mean Anteroposterior body diameter was found to be $32.15 \mathrm{~mm} \pm 1.0627$ in males and 27.04 $\mathrm{mm} \pm 0.3170$ in females. The average transverse body diameter was found to be $45.06 \mathrm{~mm} \pm 0.3637$ in males and 40.92 $\mathrm{mm} \pm 0.3074$ in females. The average interpedicular distance was found to be $26.50 \mathrm{~mm} \pm 0.39$ in males and $25.42 \mathrm{~mm}$ \pm 0.3028 in females. The average midsagittal diameter was found to be $17.96 \mathrm{~mm} \pm 0.2597$ in males and $16.94 \mathrm{~mm} \pm$ 0.2313 in females. The present study concluded that the dimensions of lumbar vertebrae for the South Indian population showed significant differences between males and females. The measurements were higher in males than females.
\end{abstract}

\section{KEY WORDS: MORPHOMETRY, LUMBAR VERTEBRAE, ANTEROPOSTERIOR DIAMETER.}

\section{INTRODUCTION}

The lumbar vertebrae consists of five vertebrae and are located in the lower back of the body. It bears all of the overlying body's weight and possesses a bigger body than thoracic and cervical vertebrae. It also provides

\section{ARTICLE INFORMATION}

*Corresponding Author: mebingeorgem.sdc@saveetha.com Received 4th Aug 2020 Accepted after revision 24th Sep 2020 Print ISSN: 0974-6455 Online ISSN: 2321-4007 CODEN: BBRCBA

Thomson Reuters ISI Web of Science Clarivate Analytics USA and Crossref Indexed Journal

\section{Clarivate
Analytics}

NAAS Journal Score 2020 (4.31) SJIF: 2020 (7.728)

A Society of Science and Nature Publication,

Bhopal India 2020. All rights reserved.

Online Contents Available at: http//www.bbrc.in/

Doi: http://dx.doi.org/10.21786/bbrc/13.8/163 easy bend and movement to the trunk region of the human body (Priyadharshini and Mohanraj, 2019). The vertebral column provides support, posture and initiates movements (Keerthika and Keerthika, 2017).They also house and secure the delicate spinal cord and nerves within their vertebral canal. Since the spinal cord passes through the vertebral canal, it is also called as spinal canal. Some devices such as rods, plates or wires can be fixed to the spinal column by screws for immobilization (Chawla et al., 2011). The accurate knowledge of the vertebral dimensions is important for diagnosis and treatment of certain vertebral diseases and instabilities.

Since ethnic and gender variations were found in vertebral dimensions, it is required to determine the origin and gender of the patient (Teo et al., 2017) (Varol et al.,

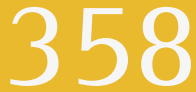


2006). Vertebrae morphology is identified to have genetic and ethnic variation but the majority of the studies were based on white population around different parts of the world, whereas a very few studies are available on Indian population (Grivas et al., 2019) . Pedicles are the strongest part of the vertebrae and it is made up of cortical bone with a small core of cancellous bone (Tiwari, Pandey and Naik, 2015). Transpedicular screw fixation has evolved into a very successful method for correcting spinal disorders by providing stable fixation and correcting spinal deformities (Lien, Liou and $\mathrm{Wu}$, 2007) (Babu and Mohanraj, 2019).

Morphology of lumbar vertebrae has an important role in clinical diagnosis of lower backache. Low back pain is a musculoskeletal condition affecting the adults (Vinaya Swetha, Yuvaraj Babu and Mohanraj, 2018). It is one of the main health problems all over the world and around $75 \%$ of the population is estimated to have experienced it at least at some point of their life (Choubisa and Babel, 2018) (Banik et al., 2019). Lumbar spinal stenosis is the common cause in older age group which is narrowing of the spinal canal in which the antero-posterior and lateral measurements of the canal are less than the normal value for the particular age and sex. This narrowing causes compression of the nerves that passes through the canal and causes pain in the lower back (Azu et al., 2016).

Other causes of low backache include abnormal orientation of joints (Mohanty et al., 2017). Many cases of spinal canal stenosis have found to have some relation with the anatomical differences. Due to the common occurrence of low backache in workers around the world, researchers have tried to focus on this region for their further study (Philipose et al., 2015) . Anatomical studies of lumbar vertebrae have been studied in different ethnic groups such as the Greek population, Western Maharashtra and in the South African population but have not yet been studied in the south Indian population. Some studies were done without taking ethnicity as a factor. The present study will serve as a database for the south Indian population.

\section{MATERIAL AND METHODS}

The study was conducted in the Department of Anatomy, Saveetha Dental College and Hospitals, Chennai and Department of Anatomy and Sri Ramachandra Medical College and Research Institute, Chennai. A total of 70 dry human lumbar vertebrae out of which 40 are of males and 30 are of females (which were recorded in the Department of Anatomy) without any gross abnormalities were collected and measured. The anteroposterior body diameter, transverse body diameter, interpedicular distance and midsagittal diameter were measured using Vernier caliper and noted down. The midsagittal diameter (MSD) was measured as the maximum anteroposterior distance of the spinal canal (figure 1 ) of each vertebrae while the interpedicular distance (IPD) was measured as the minimal distance between the medial surfaces of the pedicles on either side (figure 2). Transverse body diameter (TD) was measured as the transverse distance of each vertebral body (figure 3 ). The anteroposterior body diameter (APD) was measured as the anteroposterior distance of each vertebral body (figure 4).

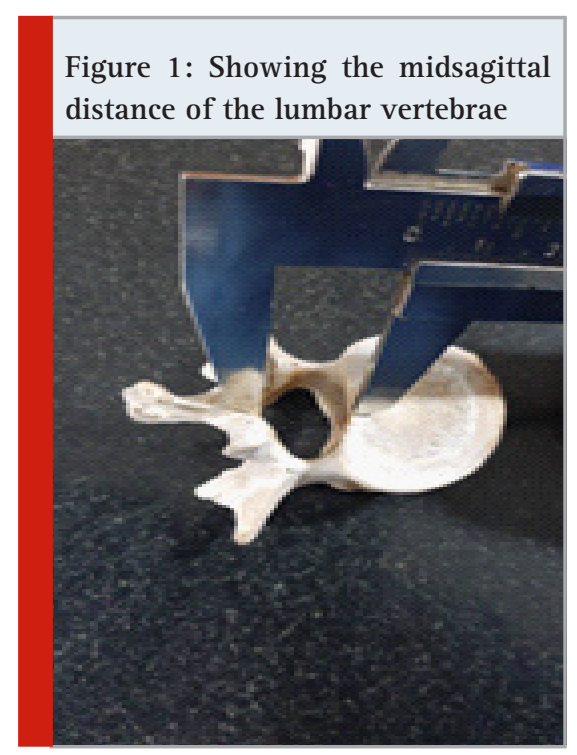

Figure 2: Showing the interpedicular distance of the lumbar vertebrae

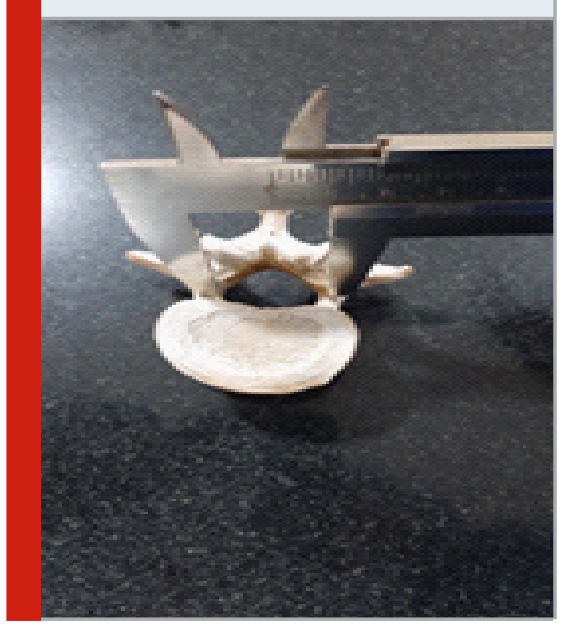

Figure 3: Showing the transverse body diameter of the lumbar vertebrae

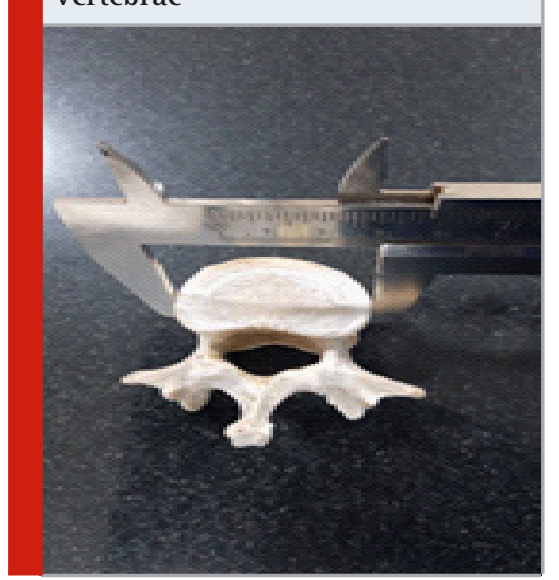




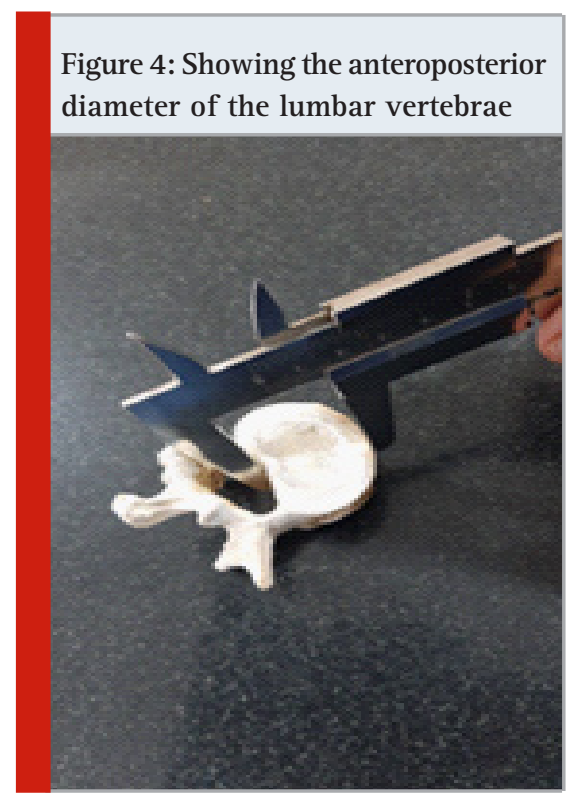

\section{RESULTS AND DISCUSSION}

Male

Table 1. Measurements of male vertebrae

\begin{tabular}{|l|c|c|}
\hline Measurements & $\begin{array}{c}\text { Mean in } \\
\mathrm{mm}\end{array}$ & $\begin{array}{c}\text { Standard } \\
\text { deviation }\end{array}$ \\
\hline Anteroposterior body diameter & 32.15 & 1.0627 \\
\hline Transverse body diameter & 45.06 & 0.3637 \\
\hline Interpedicular distance & 26.50 & 0.3900 \\
\hline Midsagittal diameter & 17.96 & 0.2597 \\
\hline
\end{tabular}

Female

Table 2. Measurements of female vertebrae

\begin{tabular}{|l|c|c|}
\hline Measurements & $\begin{array}{c}\text { Mean in } \\
\mathrm{mm}\end{array}$ & $\begin{array}{c}\text { Standard } \\
\text { deviation }\end{array}$ \\
\hline Anteroposterior body diameter & 27.04 & 0.3170 \\
\hline Transverse body diameter & 40.92 & 0.3074 \\
\hline Interpedicular distance & 25.42 & 0.3028 \\
\hline Midsagittal diameter & 16.94 & 0.2313 \\
\hline
\end{tabular}

In the present study, the mean anteroposterior body diameter was found to be $32.15 \mathrm{~mm} \pm 1.0627$ in males and $27.04 \mathrm{~mm} \pm 0.3170$ in females. The average transverse body diameter was found to be $45.06 \mathrm{~mm}$ \pm 0.3637 in males and $40.92 \mathrm{~mm} \pm 0.3074$ in females. The average interpedicular distance was found to be $26.50 \mathrm{~mm} \pm 0.39$ in males and $25.42 \mathrm{~mm} \pm 0.3028 \mathrm{in}$ females. The average midsagittal diameter was found to be $17.96 \mathrm{~mm} \pm 0.2597$ in males and $16.94 \mathrm{~mm} \pm 0.2313$ in females (table 1 and 2). From the data obtained a significant difference is seen among the males and the females dimensions indicating sexual dimorphism. All the dimensions obtained were greater in males than females but the difference in the dimensions of the vertebral body is greater than the difference in other dimensions (figure $5-8$ ).

Figure 5: Bar graph representing the association of anteroposterior diameter of the body of the lumbar vertebrae in males and females. "Males" (blue) and "Females" (orange). $\mathrm{X}$ axis represents the gender and $\mathrm{Y}$ axis represents the mean value of anteroposterior diameter of lumbar vertebrae. Males have larger anteroposterior diameter than females.

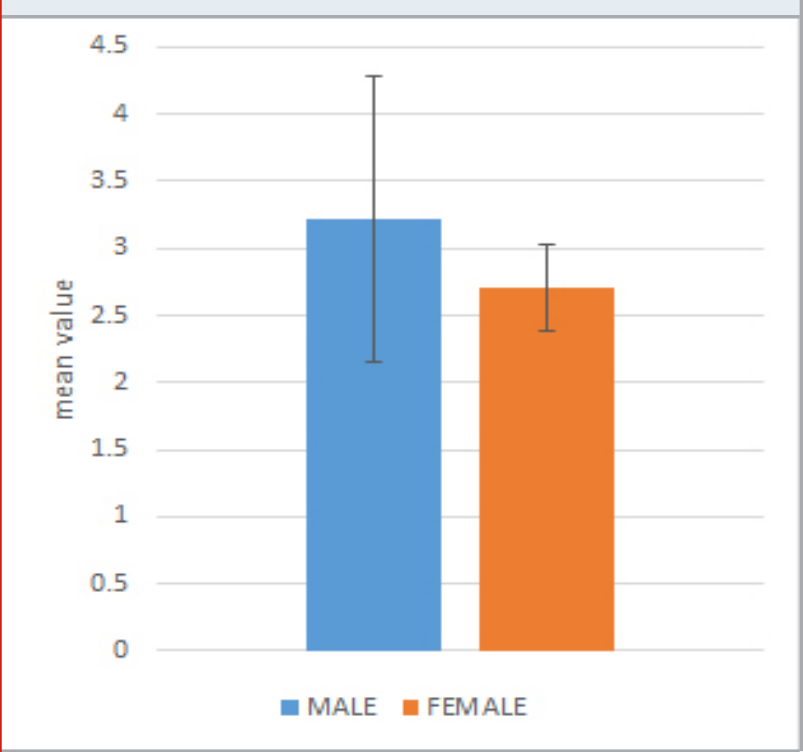

Figure 6: Bar graph representing the association of transverse diameter of the body of the lumbar vertebrae in males and females. "Males" (blue) and "Females" (orange). $\mathrm{X}$ axis represents the gender and $\mathrm{Y}$ axis represents the mean value of transverse diameter of lumbar vertebrae. Males have larger transverse diameter than females.

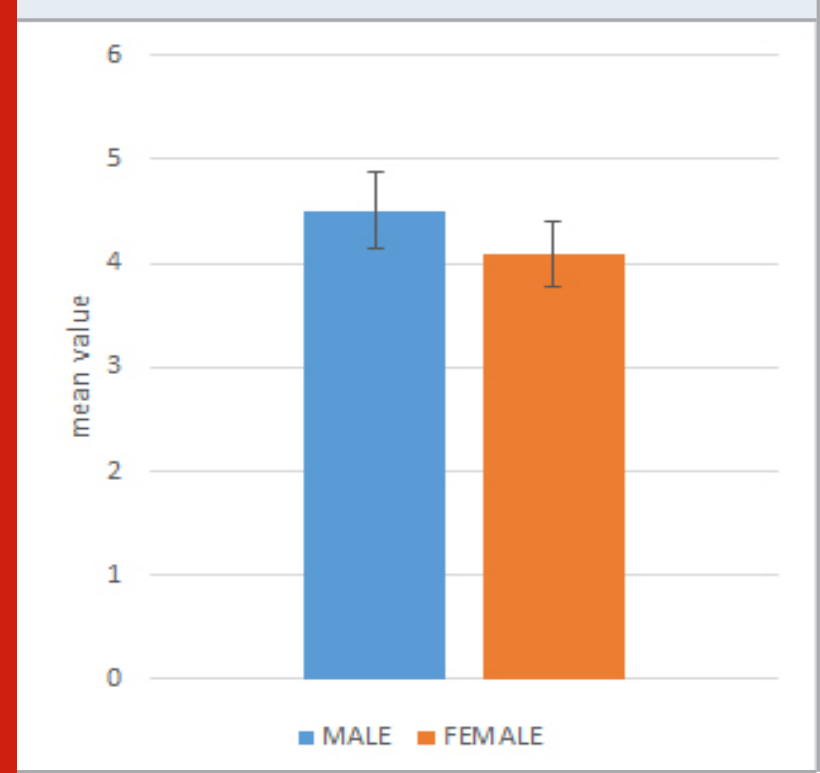


Figure 7: Bar graph representing the association of the interpedicular distance of the lumbar vertebrae in males and females. "Males" (blue) and "Females" (orange). X axis represents the gender and $\mathrm{Y}$ axis represents the mean value of interpedicular distance of lumbar vertebrae. Males have larger interpedicular distance than females.

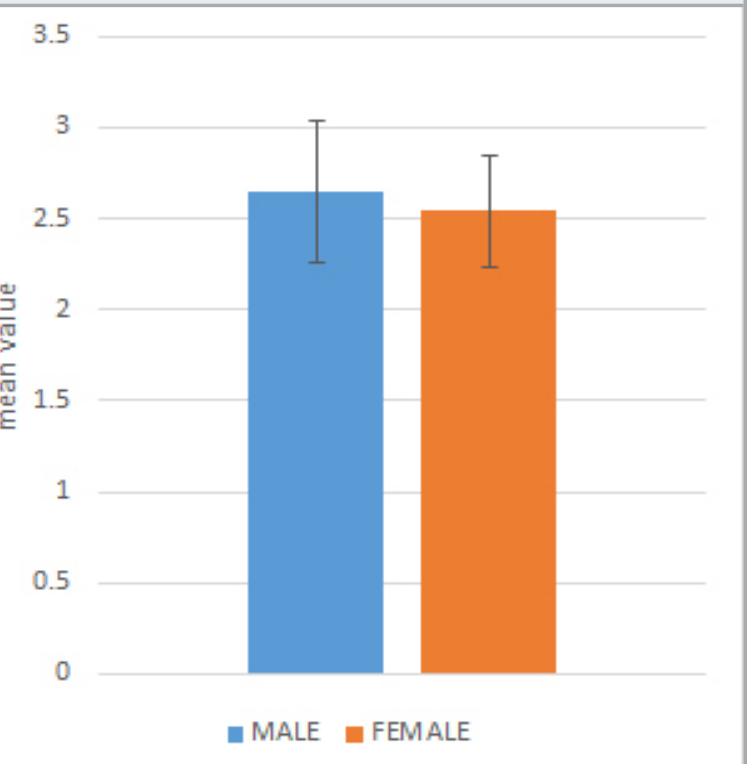

Figure 8: Bar graph representing the association of midsagittal diameter of the lumbar vertebrae in males and females. "Males" (blue) and "Females" (orange). X axis represents the gender and $\mathrm{Y}$ axis represents the mean value of midsagittal diameter of lumbar vertebrae. Male have larger midsagittal diameter than females.
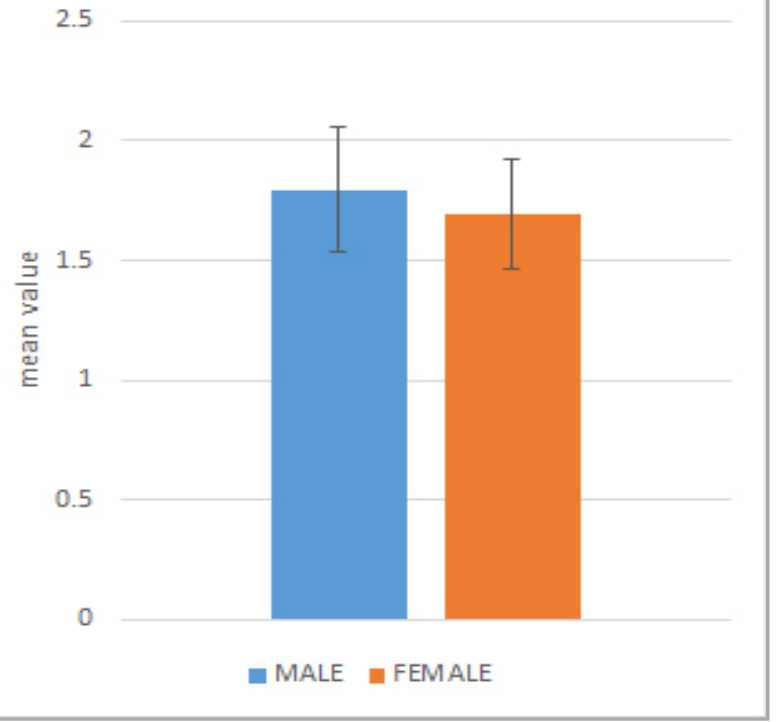

In a study done on the western maharashtra population, 420 lumbar vertebrae were measured to find out the regional and sexual differences in them. The parameters measured in this study were the anteroposterior body diameter, transverse body diameter, Interpedicular distance and midsagittal diameter which were the same as that of our study. The result when compared with previous studies had considerable differences in them. Differences in male and female lumbar vertebrae dimensions were identified with females having comparatively smaller vertebral body and smaller vertebral canal than males which is similar to our results (Jadhav et al., 2013). In a study done on Pakistani population, the vertebral dimensions were obtained for 33 males and 16 females. The measurements in this study would be more accurate than our study as it was done using computer tomography scans. The vertebral body diameters, the pedicle dimensions and the canal diameter was obtained. The vertebral dimensions were found to be higher in males than females which is similar to our results (Alam et al., 2014).

When compared with other studies, similar gender variations have been noted with the males vertebrae having larger dimensions and larger vertebral body than the female vertebrae. Variations of the dimensions are seen in different populations which could be due to environmental and genetic causes. Assessing the size of the lumbar vertebral canal is an important diagnostic tool for low back ache. Hence, these parameters could be helpful in early diagnosis of lumbar stenosis and other vertebral diseases

\section{CONCLUSION}

This study gives an understanding of the morphology of the lumbar vertebrae in the south indian population. From the study it was concluded that the lumbar vertebrae showed significant difference morphometrically for sexual dimorphism as well as for the knowledge of surgical procedures like fixation. Lumbar vertebrae morphology could be useful to find relevance in clinical diagnosis of lumbar spinal stenosis and intraspinal tumors. As Vertebrae morphology has genetic and ethnic variations, more research can be done in various populations. The dimensions obtained in this study serves as a database for the south indian population and can be compared and studied with different sets of population.

Conflict of interest: The author declares that there was no conflict of interest in the present study.

\section{REFERENCES}

Alam, M. M. Et Al. (2014) 'lumbar Morphometry: A Study Of Lumbar Vertebrae From A Pakistani Population Using Computed Tomography Scans', Asian Spine Journal, 8(4), Pp. 421-426. Doi: 10.4184/Asj.2014.8.4.421.

Azu, 0. 0. Et Al. (2016) 'morphometric Study Of Lumbar Vertebrae In Adult South African Subjects', International Journal Of Morphology = Revista Internacional De Morfologia, 34(4), Pp. 1345-1351. Available At: https:// bit.ly/3nfCZJ5

Babu, B. V. And Mohanraj, K. G. (2019) 'osteometric Analysis Of Thoracic Vertebrae With Reference To Pedicle And Its Clinical Applications', Drug Invention Today, 11(10). Available At: https://bit.ly/3jsVU0i 
Banik, S. Et Al. (2019) 'morphometric Analysis of Lumbar Vertebrae And Its Applied Clinical Importance', International Journal of Anatomy And Research, Pp. 6381-6386. Doi: 10.16965/Ijar.2019.122.

Chawla, K. Et Al. (2011) 'morphometry Of The Lumbar Pedicle In North West India', Eur J Anat, 15(3), Pp. 155-161. Available At: https://bit.ly/3lmjm07

Choubisa, L. And Babel, H. (2018) 'morphometric Study Of Pedicles Of Dried Adult Human Lumbar Vertebrae In Udaipur Zone', Int J Anat Res, 6(3.3), Pp. 5660-5666. Available At: Https://Pdfs.Semanticscholar.Org/40be/3 b7d344d45aebb2a55ba4fd6c061f4047980.Pdf.

Grivas, T. B. Et Al. (2019) 'morphometric Characteristics Of The Thorac冈lumbar And Lumbar Vertebrae In The Greek Population: A Computed Tomography-based Study On 900 Vertebrae-“Hellenic Spine Society (Hss) 2017 Award Winner”, Scoliosis And Spinal Disorders. Doi: 10.1186/S13013-019-0176-4.

Jadhav, A. S. Et Al. (2013) 'osteological Study Of Lumbar Vertebrae In Western Maharashtra Population', Journal Of The Anatomical Society Of India, 62(1), Pp. 10-16. Doi: 10.1016/S0003-2778(13)80005-6.

Keerthika And Keerthika (2017) 'vertebral Synostosis And Its Clinical Significance', Research Journal of Pharmacy And Technology, P. 3643. Doi: 10.5958/0974360x.2017.00661.8.

Lien, S.-b., Liou, N.-h. And Wu, S.-s. (2007) 'analysis of Anatomic Morphometry of The Pedicles And The Safe Zone For Through-pedicle Procedures In The Thoracic And Lumbar Spine', European Spine Journal: Official Publication Of The European Spine Society, The European Spinal Deformity Society, And The European Section Of The Cervical Spine Research Society, 16(8),
Pp. 1215-1222. Doi: 10.1007/S00586-006-0245-2. Mohanty, S. P. Et Al. (2017) 'morphometric Study of The Orientation Of Lumbar Zygapophyseal Joints In A South Indian Population', Journal of Orthopaedic Surgery , 25(3), P. 2309499017739483. Doi: $10.1177 / 2309499017739483$.

Philipose, S. Et Al. (2015) 'morphometric Study Of Pedicles Of Lumbar Vertebrae In Southern India', Journal Of Evidence Based Medicine And Healthcare, Pp. 6182-6191. Doi: 10.18410/Jebmh/2015/854.

Priyadharshini, S. And Mohanraj, K. G. (2019) 'morphological And Morphometrical Analysis of Lumbar Vertebrae In Relation To Pedicle And Its Clinical Implications', Drug Invention Today, 12(9). Available At: https://bit.ly/2Sk8jbF

Teo, E. C. Et Al. (2017) 'morphometric Analysis Of Human Second Cervical Vertebrae (Axis)', Journal of Spine, 6(399), P. 2. Available At: https://bit.ly/2HT55db

Tiwari, A., Pandey, S. And Naik, D. C. (2015) 'morphometric Study Of Atypical Lumbar Vertebrae And Its Physiological Correlation', International Journal Of Medical Science And Public Health. Dipika Charan, 4(2), P. 262. Available At: Https://Core.Ac.Uk/Download/ Pdf/33344400.Pdf.

Varol, T. Et Al. (2006) 'comparative Morphometry of The Lower Lumbar Vertebrae: Osteometry In Dry Bones And Computed Tomography Images Of Patients With And Without Low Back Pain', The Journal of International Medical Research, 34(3), Pp. 316-330. Doi: $10.1177 / 147323000603400312$.

Vinaya Swetha, T., Yuvaraj Babu, K. And Mohanraj, K. G. (2018) 'survey On Back Pain', Drug Invention Today, 10(12). Available At: https://bit.ly/3jwpD9e 